\title{
Research on Problems and Strategies of "Learning" from the Perspective of Physical Education Curriculum
}

\author{
Ran Cheng, Ran Sun, Qiang Li \\ School of Sports and Health Sciences, Chongqing Normal University, Chongqing 401331, China
}

\begin{abstract}
Using literature review, questionnaire survey, mathematical statistics and other research methods, combined with the previous research results of the research team, systematically sort out the problems of "learning" in the "learning, training, competition, and use" physical education curriculum, and how to solve the problems. The strategic research of the Chinese Academy of Sciences aims to promote the scientificization of "learning" in the teaching of physical education courses, thereby improving the quality and efficiency of physical education courses.
\end{abstract}

Key words: Physical Education Curriculum; Learning; Problems and Strategies

Publication date: April, 2021; Publication online: 30 April, 2021

*Corresponding author: Ran Cheng, 316400633@qq.com

The "learning, practicing, competition, and use" physical education curriculum is aimed at a complete knowledge chain formed by a single link in classroom teaching that cannot satisfy sports knowledge (sports skills are internalized into sports skills). It is a phenomenon of incomplete courses. Formed into a comprehensive physical education curriculum (as shown in Figure 1) that extends to the complete links of teaching, training, competition, and use inside and outside the class, and is organically activated into four parts of "learning", "practice", "competition" and "use". New Concept and Cognition of the Structure of Physical Education Curriculum.

"Learning" is the process of imitating, experiencing, feeling, and absorbing the formation of motor skills, and rough movement techniques are formed through "learning". "Practicing" is a process of repetition of movements and thoughts in the formation of motor skills, a process of deeply feeling the economy and rationality of sports technology and achieving a good synergy between the brain and muscles, which is formed by basically completing the internalization of sports technology. Theprocess of one's own ability is the process of refinement of sports technology and the key process of forming sports skills. "Competition" is the process of testing, correcting, improving and fine-tuning the formation of sports skills. "Use" refers to the process of achieving exercise and fitness habits and being able to accurately use and transfer the acquired exercise skills. It is the proficient, conscious and automatic use of exercise skills in various learning and working environments to exercise, strengthen the mind, strengthen intelligence and shape perfection. The process of personality. The whole process of "learning, training, competition, and use" is centered around the formation of motor skills. As shown in Figure 2, the various parts are juxtaposed, independent and blended with each other. "Learning, practicing, competing, and using" is the organic carrier of the formation process of motor skills.

\section{Research method}

\subsection{Literature data method}

Through the literature platform, this research uses the terms "sports curriculum", "sports teaching", "sports teaching goals", "sports teaching reform", "sports teaching evaluation" and other terms as search conditions to search for domestic and foreign experts and scholars on universities, middle schools and universities. Related literature on physical education in elementary schools, systematically interpret relevant documents, guidelines and policies issued by the country in physical education, and the "Sports and Health 
Curriculum Standards." Organize, summarize and analyze the literature on physical education teaching, understand the latest trends in this type of research, and pave the way for the theoretical basis of this research.

\subsection{Questionnaire survey method}

This article has compiled the "Questionnaire for Physical Education Teachers in Universities, Middle Schools, and Primary Schools", "Questionnaires for Primary and Middle School Students", and "Questionnaires for College Students". It uses two methods to distribute the questionnaire survey: one is to use random sampling. Distribute physical education teachers and students; secondly, to make the data reliable, it is distributed to universities, middle schools and primary schools in surrounding provinces and cities where physical education classes are better implemented. A total of 300 copies of the "Questionnaire for Physical Education Teachers in Universities, Middle Schools, and Primary Schools" were issued, and 271 questionnaires were returned, with a recovery rate of $90.3 \%$, of which 264 were valid questionnaires, with an effective recovery rate of $97.4 \%$; for the "Questionnaire for Primary and Middle School Students", a total of 1000 questionnaires were issued and 942 questionnaires were returned, with a recovery rate of $94.2 \%$, of which 882 were valid questionnaires, with an effective recovery rate of $93.6 \%$; a total of 500 copies of the "University Student Questionnaire" were issued, and 446 questionnaires were returned, with a recovery rate of $89.2 \%$, of which effective 395 questionnaires, with an effective recovery rate of $88.5 \%$

\subsection{Interview method}

According to the current basic situation of primary and middle school physical education courses and related problems in obtaining sports skills, design an interview outline, interview some experts and scholars from different aspects, and organize the interview results, and summarize the suggestions of experts and scholars and their emergence. The solution to the problem provides auxiliary support for the research results of this article.

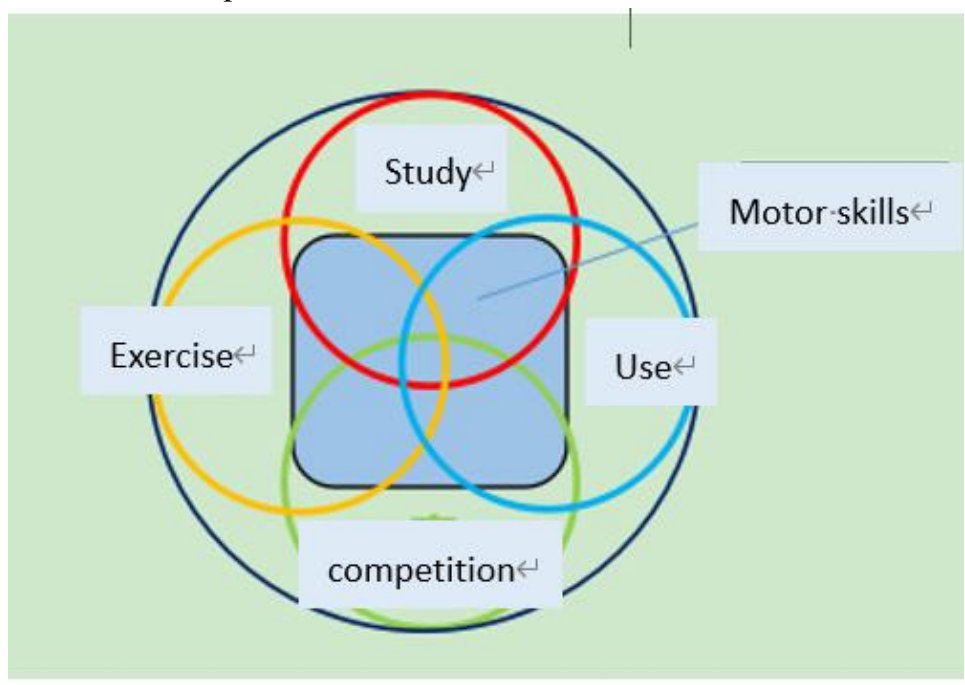

Figure 1. The structure of the physical education curriculum

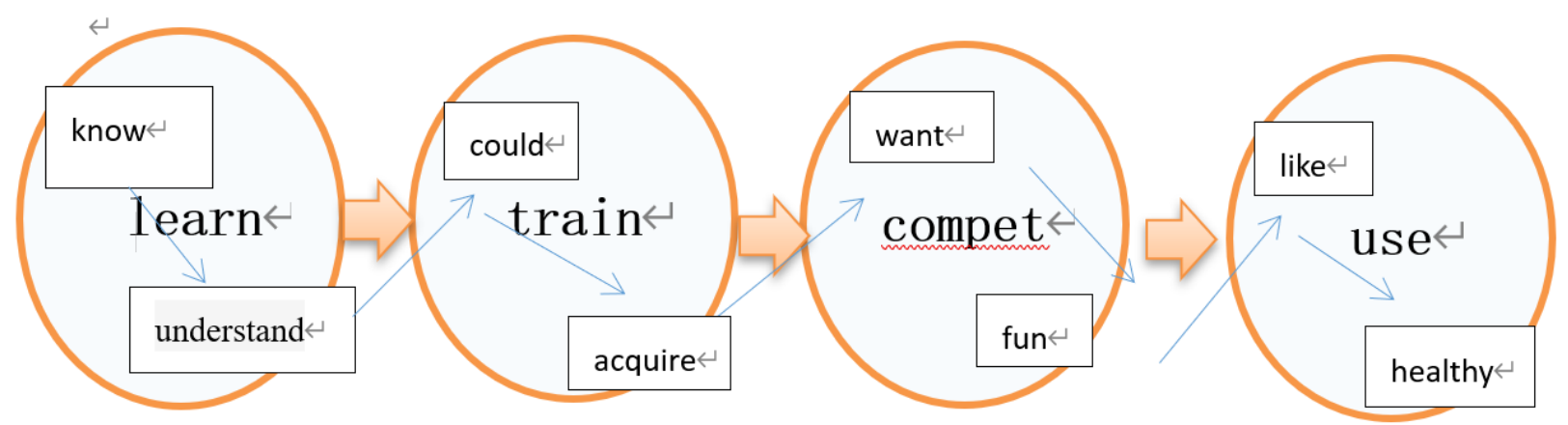

Figure 2. The relationship between the starting point and the end point of each stage in the large-scale curriculum model of "learning, practicing, competing, and using" 


\section{Carding and analysis of the existing problems}

\section{of "learning" in the current physical education}

\section{class}

"Learning and teaching" in the physical education curriculum is a bilateral process of learning. Therefore, the problems of teachers' "teaching" can reflect the problems of students' "learning".

\subsection{Wrong learning-deviation from the main point}

Most of the things that are wrong in sports technology learning are due to the teacher's formation in the initial teaching process. The teacher instills a small wrong concept into the students in the early stage of teaching, which will be enlarged continuously during the students' learning process, that is, the so-called "the smallest difference is thousands of miles", and it will eventually be a wrong action stereotype.

\subsection{Inaccurate learning-ambiguous}

In physical education, teachers are not allowed to teach, and students are not allowed to learn. For example, in a college tennis class, observing that the teacher said a key word "Stay steady" when teaching a serve, it turned out that many students stood straight, almost weak to serve or got off the net. In fact, the motivation is forward after a serve, and the body will definitely move forward. Therefore, the teacher is not accurate, the key points are not grasped, and the students do not understand what a serve is and how to serve.

\subsection{Incomplete learning-missing knowledge}

In physical education, the learning of sports technology usually only involves part of the content. Teachers often

It can be seen from Table 2 that only more than half of the teachers believe that they are very accurate in technical teaching, $43 \%$ of teachers think that the accuracy is fair, and $3.5 \%$ of teachers think that they are not accurate.

It can be seen from Table 3 that $14 \%$ of college students choose some basic content in the selection of teaching content, which leads to incomplete sports technology learning by students. For example, in the teaching of basketball class, students only learn basketball skills from elementary school to university, only dribbling, passing, and shooting skills. For basketball skills, low hand layup skills on the move, jump shot skills, basketball rules, etc. Basically no knowledge points, students lack the technical composition of the entire basketball game, and their understanding of basketball is not comprehensive.

It can be seen from Table 1 that $34.2 \%$ of teachers believe that they are very comprehensive in sports technology teaching, $58.7 \%$ of teachers believe that they have only taught sports technology basically and comprehensively, and $7.1 \%$ of teachers believe that they are not in sports technology teaching. Not very comprehensive. It shows that the teacher basically completes his own teaching task, and does not teach a certain sport technique profoundly and comprehensively.

\subsection{I'm not good at learning-just a little bit}

There has been a long-term phenomenon of "flickering" in physical education, that is, the phenomenon of low-level repetitive learning, so how can teachers teach well? Try the following cases: When "learning tennis forehand technique", students of different levels are required to complete different goals.

Students with good strength and strong control complete the bottom line pull and require the number of rounds. On the contrary, shorten the pairing distance and reduce the number of rounds. In this way, students at different levels can achieve their goals through serious study and hard practice.

think that teachers' classroom teaching is very accurate, $60.2 \%$ of students think that the accuracy of teacher's classroom teaching is average, and $25.8 \%$ of students think that teacher's classroom teaching is not accurate.

Table 1. Statistics on whether teachers are comprehensive in sports technology teaching.

\begin{tabular}{llll}
\hline Options & Comprehensive & Basically comprehensive & Not comprehensive \\
\hline Number of people & 81 & 155 & 19 \\
Patio & $34.2 \%$ & $58.7 \%$ & $7.1 \%$ \\
\hline
\end{tabular}

Table 2. Statistics on whether the teacher is accurate to the requirements of each movement detail when teaching sports techniques.

\begin{tabular}{lllll}
\hline Options & Very accurate & Fairly & Inaccurate & \\
\hline Number of people & 142 & 114 & 8 & \\
Patio & $53.5 \%$ & $43.0 \%$ & $3.5 \%$ & \\
\hline Distributed under creative commons license 4.0 & $\mathbf{6 9}$ & & Volume 5; Issue 4
\end{tabular}


Table 3. Statistics on whether the teacher is accurate to the requirements of each action detail when college students are studying in the physical education class

\begin{tabular}{llll}
\hline Options & Very accurate & Fairly & Inaccurate \\
\hline Number of people & 55 & 238 & 102 \\
Patio & $14.0 \%$ & $60.2 \%$ & $25.8 \%$ \\
\hline
\end{tabular}

Table 4. Statistics on whether the teachers are accurate to the requirements of each action detail when the students in the middle and elementary schools study in the physical education class

\begin{tabular}{llll}
\hline Options & Very accurate & Fairly & Inaccurate \\
\hline Number of people & 152 & 511 & 219 \\
Patio & $18.3 \%$ & $57.9 \%$ & $24.8 \%$ \\
\hline
\end{tabular}

It can be seen from Table 4 that $18.3 \%$ of primary and middle school students think that teachers' classroom teaching is very accurate, $57.9 \%$ of students think that the accuracy of teacher's classroom teaching is average, and $24.8 \%$ of students think that teacher's classroom teaching is not accurate.

In summary, in the eyes of teachers, half of the teachers think that they are very accurate and half of the teachers think that the accuracy is average; in the eyes of students, more than half of them think that the accuracy is average, and the number of inaccurate exceeds the number of very precise. It shows that the accuracy of technical teaching of teachers in physical education is relatively average, which leads to the general situation of students' learning technology, that is, "not learning well".

\subsection{Learning is not new-outdated knowledge}

In physical education, there is a lack of innovation in content and form.

It can be seen from Table 5 that teachers pay less attention to some sports policies and documents issued by the state.

It can be seen from Table 6 that $66.2 \%$ of the teachers will bring forth the new in the teaching process, and $33.8 \%$ of the teachers did not bring forth the new.

It can be seen from Table 7 that $63.7 \%$ of college students believe that physical education teachers will introduce new ideas, and 36.3 college students believe that physical education teachers will not introduce new ideas.

In summary, more than $30 \%$ of teachers have not introduced the old, and the phenomenon of outdated knowledge is still relatively large, and innovations in content and form are needed.

Table 5. Statistics of teachers' attention to sports policies, regulations, documents, and conference spirit issued by the national education administrative department

\begin{tabular}{|c|c|c|c|c|c|}
\hline Options & $\begin{array}{l}\text { Very } \\
\text { concerned }\end{array}$ & $\begin{array}{l}\text { Slightly } \\
\text { concerned }\end{array}$ & General & $\begin{array}{l}\text { Not very } \\
\text { concerned }\end{array}$ & Not concerned \\
\hline Number of people & 36 & 61 & 102 & 43 & 22 \\
\hline Patio & $13.6 \%$ & 23.1 & $38.6 \%$ & $16.2 \%$ & $8.5 \%$ \\
\hline
\end{tabular}

Table 6. Statistics on whether teachers will introduce new ideas in the teaching process

\begin{tabular}{lll}
\hline Options & will & will not \\
\hline Number of people & 175 & 89 \\
Patio & $66.2 \%$ & $33.8 \%$
\end{tabular}

Table 7. Statistics on whether teachers will introduce new ideas when college students study in physical education classrooms

\begin{tabular}{lll}
\hline Options & will & will not \\
\hline Number of people & 252 & 143 \\
\hline
\end{tabular}




\begin{tabular}{lll}
\hline Patio & $63.7 \%$ & $36.3 \%$
\end{tabular}

Table 8. Statistics on whether teachers in primary and middle school students learn in physical education classes.

\begin{tabular}{lll}
\hline Options & will & will not \\
\hline Number of people & 626 & 256 \\
Patio & $70.9 \%$ & $29.1 \%$ \\
\hline
\end{tabular}

\subsection{Insufficient learning-lack of depth and breadth}

Depth is "fine", and breadth is "bo". At present, in the physical education classes of universities, middle schools and elementary schools, some teachers obviously lack the depth and breadth in the process of teaching sports skills. The teacher did not take care of the entire "face" of sports technology, nor did he analyze and dig the difficult parts of the teaching content in depth, resulting in students neither learning deeply nor learning extensively. It can be seen from Table 9 that teachers are basically progressive in teaching content. It can be seen from Table 10 that $54.9 \%$ of college students believe that the learning content is different from the past, and $45.1 \%$ of college students believe that the learning content is no different from the past.

\subsection{Learning does not "progress"-lack of progress}

Progressive, that is, in a certain order, from shallow to deep. No matter what kind of sports technology is learned, it is a purposeful, conscious, and planned process. Motor skills are guided by sports technology, and sports technology has the nature of formal, complete, progressive, and systematic. In the current university public physical education class, the teaching of a certain sports technique is still at the initial stage, and this stage should be completed by middle and elementary schools. No matter what level the students belong to, there is still no change in the content of the sports technology teaching of the same item in the physical education class. As a result, the content of learning remains unchanged from elementary school to junior high school to university.

It can be seen from Table 11 that $47.8 \%$ of the students believe that the learning content is the same as in the past, and $52.2 \%$.

of the students believe that the content is different and have certain difficulty requirements.

It can be seen that although teachers believe that their teaching is progressive, nearly half of the students believe that the learning content is the same as in the past, without any difference. Looking at the above, the inherent logical relationship of the "teaching (learning)" problem is shown in Table 12 below.

Table 9. Shows whether the teaching content of teachers will be progressive with the increase of students' grades.

\begin{tabular}{lll}
\hline Options & Have & No \\
\hline Number of people & 238 & 26 \\
Patio & $90.1 \%$ & $9.9 \%$ \\
\hline
\end{tabular}

Table 10. Statistics on whether the learning content of college students is different from the past when they study in the physical education class.

\begin{tabular}{lll}
\hline Options & Have & No \\
\hline Number of people & 217 & 178 \\
Patio & $54.9 \%$ & $45.1 \%$ \\
\hline
\end{tabular}

Table 11. Statistics on whether the learning content of primary and middle school students is the same as in the past when they study in physical education classes.

\begin{tabular}{llll}
\hline Options & The same & $\begin{array}{l}\text { He content is the same, the teacher } \\
\text { teaches differently, }\end{array}$ & $\begin{array}{l}\text { The content is different, there are } \\
\text { certain difficulty requirements }\end{array}$ \\
\hline Number of people & 192 & 231 & 459 \\
\hline
\end{tabular}




\begin{tabular}{llll}
\hline Patio & $21.7 \%$ & $26.1 \%$ & $52.2 \%$
\end{tabular}

Table 12. The internal logical relationship of the "teaching (learning)" problem

\begin{tabular}{|c|c|c|}
\hline $\begin{array}{l}\text { Problems with the principle of } \\
\text { "teaching (learning)" }\end{array}$ & performance & performance \\
\hline Wrong & What is taught is wrong & $\begin{array}{l}\text { After the tennis ball is served, the body is } \\
\text { greeted forward, and the teacher teaches to } \\
\text { "stand firmly." }\end{array}$ \\
\hline Not allowed & $\begin{array}{l}\text { The main points of the } \\
\text { technique are vague and not } \\
\text { accurate enough }\end{array}$ & $\begin{array}{l}\text { Tennis volley, the teacher did not specify } \\
\text { under what circumstances the racket face is } \\
\text { open or closed }\end{array}$ \\
\hline Incomplete & $\begin{array}{l}\text { There is a problem with the } \\
\text { integrity of the content, it is } \\
\text { a problem }\end{array}$ & $\begin{array}{l}\text { In tennis volleys, the teacher only teaches } \\
\text { "intercept", not "strike", and no specific } \\
\text { application. }\end{array}$ \\
\hline Not refined & $\begin{array}{l}\text { The teaching process is not } \\
\text { refined enough and lacks } \\
\text { detailed requirements }\end{array}$ & $\begin{array}{l}\text { In tennis forehand, students with good } \\
\text { strength can hit the ball near the bottom line, } \\
\text { but students with poor strength cannot do it, } \\
\text { but the teacher did not ask for it. }\end{array}$ \\
\hline Not new & $\begin{array}{l}\text { Not receiving new } \\
\text { knowledge, there is lag }\end{array}$ & $\begin{array}{l}\text { For tennis volleys, students practice blindly } \\
\text { without watching and analyzing some game } \\
\text { videos. }\end{array}$ \\
\hline Insecure & $\begin{array}{l}\text { There is a problem with the } \\
\text { teaching method, which } \\
\text { does not fully motivate } \\
\text { students }\end{array}$ & $\begin{array}{l}\text { Tennis serve, the students who always can't } \\
\text { hit the ball or fly away gradually lose interest } \\
\text { and have no enthusiasm for learning. }\end{array}$ \\
\hline Not enough & $\begin{array}{l}\text { The lack of depth and } \\
\text { breadth is a matter of degree }\end{array}$ & $\begin{array}{l}\text { Tennis forehand hits the ball with speed and } \\
\text { angle on time. Once a mistake is made, it is } \\
\text { very outrageous. }\end{array}$ \\
\hline Not enter & $\begin{array}{l}\text { The content is repetitive, not } \\
\text { progressive }\end{array}$ & $\begin{array}{l}\text { Students have taken tennis lessons in high } \\
\text { school, and the tennis lessons in college still } \\
\text { start with how to hold a racket, and the } \\
\text { content is almost the same. }\end{array}$ \\
\hline
\end{tabular}

\section{Conclusions and recommendations}

\subsection{Conclusion}

Based on the theory of the physical education curriculum, teachers' "teaching" is scientific, which promotes the scientific "learning" of students, which is conducive to the acquisition of sports skills by students. At present, in physical education classes of universities, middle schools and elementary schools, due to various problems in "learning", it is not conducive to the acquisition of sports skills of students. Correct and reasonable "learning" is the basis for students to acquire sports skills. For the same sports event, the "learning" is progressive from elementary school to university, which is conducive to students' grasp of sports technology more firmly.

\subsection{Suggestions}

In the physical education classrooms of universities, middle schools and primary schools, sports skills should be acquired through scientific "learning" To fully understand the importance of "learning", it is even more important to understand the "learning" of science. Teachers should adopt more scientific teaching methods to enable students to learn sports techniques. Using "learning" to help students acquire sports skills, promote students' effective sports participation, and ultimately achieve the improvement of students' physical fitness in colleges, middle schools, and primary schools, has 
a high implementation value.

Vigorously solve the problems of "learning", improve the quality of physical education classes and students' athletic ability

We should vigorously solve various problems in "learning", that is, vigorously solve various problems existing in the teaching principles and teaching content of teachers. Teachers should conduct in-depth investigations to find weak links. Efforts to improve their classroom teaching, improve classroom efficiency, and use diversified teaching methods to stimulate students' interest and enthusiasm for exercise. Physical education classes in universities, middle schools, and elementary schools should focus on the "learning" stage to lay a solid foundation for the later stage . "Learning" is the initial stage of the formation of sports technology. In this most basic stage, teachers have problems in "teaching", which will directly cause students to have problems in "learning". In the initial stage, teachers should adopt reasonable and correct teaching methods to teach the right sports technology, so that students can learn the right sports technology, and better lay the foundation for the later stage. For the same sport, students are at different levels and should set different progressive teaching goals. Teachers should set a progressive teaching goal for students from elementary school to university while studying in the same sport. According to the students' grades from high to low, the depth, breadth and difficulty of the goals are also from high to low.

\section{References}

[1]Ministry of Education of the People's Republic of China. "Opinions on Strengthening Youth Sports and Strengthening Youth Physical Fitness"[S]. Jiao Ti Yi [2007] No. 14, 2007-64.
[2] Ministry of Education of the People's Republic of China. "Opinions on Strengthening School Physical Education to Promote the All-round Development of Students' Physical and Mental Health"[S]. Education Art [2016] No. 27, 2016-421.

[3] Department of Basic Education, Ministry of Education. Interpretation of Physical Education (and Health) Curriculum Standards[M]. Hubei and Hubei Education Press, 2002, 5(18): 7-9.

[4] Zhenming Mao, Li, Zhao Shaowei Pan. School Physical Education[M]. Beijing: Higher Education Press, 2001: 35-36. [5] Yanfei Chen, Wenme Baii, Zhenming Mao. On the concept and level of physical education teaching methods[J]. Journal of Tianlu Institute of Physical Education, 2006, 21(2): 180-182.

[6] Sumei Yu, Zhenming Mao. The realization of the "dynamic structure" system of the four-element rest education in the inner and outer layers[J]. Beijing Sport University News, 2008, 31(11): 1531-1533

[7] Sumei Yu, Zhenming Mao. Establish a classification system of physical education methods from a threedimensional view [J]. Journal of Shanghai University of Sport, 2009, 33(2): 79-82

[8] Tyler R. (1949), Basic Principles of Curriculum and Instruction, Chicago, IL: The University of Chicago Press, P.1. [9] Cremin, Lawrance A. Curriculumn-Making in the United States, in Teachers College Record, Vol. 73 (December 1971), pp. 207, 212. 